\title{
3D Simulative Investigation of Heat Transfer Enhancement Using Three Vortex Generator Types Surrounding Tube in Plate Fin Heat Exchanger
}

\author{
Stefan Mardikus ${ }^{1, *}$, Petrus Setyo Prabowo ${ }^{2}$, Vinsensius Tiara Putra ${ }^{3}$, \\ Made Wicaksana Ekaputra ${ }^{1}$, and Juris Burlakovs ${ }^{4}$ \\ ${ }^{1}$ Department of Mechanical Engineering, Sanata Dharma University, Jl. Affandi, Mrican, \\ Caturtunggal, Depok, Sleman, DIY 55281 Indonesia \\ ${ }^{2}$ Department of Electrical Engineering, Sanata Dharma University, Jl. Affandi, Mrican, Caturtunggal, \\ Depok, Sleman, DIY 55281 Indonesia \\ ${ }^{3}$ Department of Mechanical Engineering, Gajah Mada University, Jl. Grafika No.2, Senolowo, \\ Sinduadi, Yogyakarta 55284 Indonesia \\ ${ }^{4}$ Post Doc in Environmental Science and Engineering, Department of Biology and Environmental \\ Science, Linnaeus University, SE-391 82 Kalmar, Sweden
}

\begin{abstract}
Vortex generator is a method to enhancing of heat exchanger performance but still have some disadvantages when the heat transfer performance increase. One of the disadvantage using vortex generator is high pressure drop. This investigation will be compared three type vortex generators to result the overall performance of heat transfer around tube in plate fin heat exchanger. The three types of vortex generator to investigate are rectangular winglet type, delta winglet type, and trapezoidal winglet type in laminar flow. The result showed that using the kind of trapezoidal winglet pair type in the plate fin and tube heat exchanger consist of six rows of round tube with two neighboring fins form a channel better performance than two types vortex generators such as rectangular winglet type and delta winglet type. The heat transfer coefficient when use trapezoidal winglet type was increased almost same with rectangular winglet type and pressure drop was decreased more than delta winglet type.
\end{abstract}

Keywords: Longitudinal vortices, nusselt number, pressure drop.

\section{Introduction}

In many industrial areas, such as chemical and food process, automobile, power plant, HVACR (heating, ventilating, air conditioning and refrigeration), and petrochemical process, heat exchangers are devices used to improve energy efficiency and heat transfer enhancement. Significant criteria in fabrication of heat exchanger types are high efficiency, small size, light weight and low cost [1]. In order to increase heat transfer performance, enhancement heat transfer must be developed to increase significant heat transfer

\footnotetext{
*Corresponding author: stefan@usd.ac.id
} 
coefficient. Many efforts have been produced to increase heat transfer coefficient. One of methods of improving heat transfer performance is by using vortex generators. Vortex generators can increase the enhancement heat transfer but it can't loss additonal penalty in the pressure drop [2]. Vortex generation is a new method of enhancing air-side heat transfer. Vortex generators such as wing and winglet can introduce vortices into flow around fin and tube heat exchanger, causing heat transfer enhancement. Vortex can be classified into two categories based on axis on these vortices: transverse vortices and longitudinal vortices. Longitudinal vortices have flow direction of axes parallel to main flow direction and transverse vortices have flow direction of perpendicular to main flow direction. Vortices are generated when fluid flow through vortex generators and due to the friction and separation on the edge of the vortex generator [3].

A modified rectangular longitudinal vortex generator (LVG) by Chunhua Min et al. [4] obtained by cutting off the four corners of rectangular wing. Fluid flow and heat transfer characteristics of this LVG mounted the rectangular channel are experimentally investigated. It was observed that the down-sweep of longitudinal vortices is beneficial to heat transfer enhancement. There are three mechanisms for passive heat transfer enhancement, (i) developing boundary layers, (ii) swirl and (iii) flow desstabilitation [3]. In the noted of above investigation, there is not studies of efforts to reduce pressure drop in using vortex generators and above investigation a much only focus to increase high heat transfer coefficient of heat transfer enhancement. In the present study, 3D simulation investigation of heat transfer enhancement using three type vortex generator around tube in plate fin heat exchanger.

\section{Model description}

In this study, plate fin and tube configuration is investigated. In Figure 1, there was three schematic models of heat exchanger. Figure 2 represented the top view of the computational domain plate fin and tube heat exchanger with vortex generator. The plate fin and tube heat exchanger consist of six rows of round tube with two neighboring fins form a channel. In present study, schematic model of plate fin and tube heat exchanger with rectangular is shown in Figure 3 with a pair rectangular winglets of 150 angle based on center line tube was symmetrically mounted on the fin surface adjacent to heat transfer tube. Figure 4, the delta winglet pairs which based on same angle of rectangular winglet gave for fin and tube heat exchanger. Figure 5 showed the trapezoid winglet pairs of vortex generator. The six tube configurations were used with diameter of the tube by $10.67 \mathrm{~mm}$. First tube was located at $12.7 \mathrm{~mm}$ from the upstream fin edge. Distance between the tubes was $25.4 \mathrm{~mm}$ and the tube rows was placed in the center line. Rectangular, delta and trapezoid winglets had same configuration. The height of the winglets was $3.5 \mathrm{~mm}$ and the length was as same as the tube diameter. Vortex generators was placed in "common flow up" orientation. Distances between fins was $3.63 \mathrm{~mm}$. Fin width was $25.4 \mathrm{~mm}$ and the fin length was $125.4 \mathrm{~mm}$.

\subsection{Numerical methods}

The computational mesh was generated by using ANSYS Meshing. Because of the complexity of the computational domain, it was difficult to use single mesh structure for the computational domain. In order to make easy of mesh structure, the upstream extended region and downstream region use a structured hexahedral mesh because of its simplicity. For the delta winglet, rectangular winglet and trapezoidal winglet vortex generators region, it is complex and unstructured hexahedral. The meshes were generated much finer in the tube and winglet regions and much coarser in the upstream and downstream region. In 
order to describe the mesh, it can be seen in Figure 6. The Navier-Stokes and energy equation with boundary condition equation were finished by computational fluid dynamics program (Fluent). The convective term in governing equation was discretized with the second order upwind scheme.

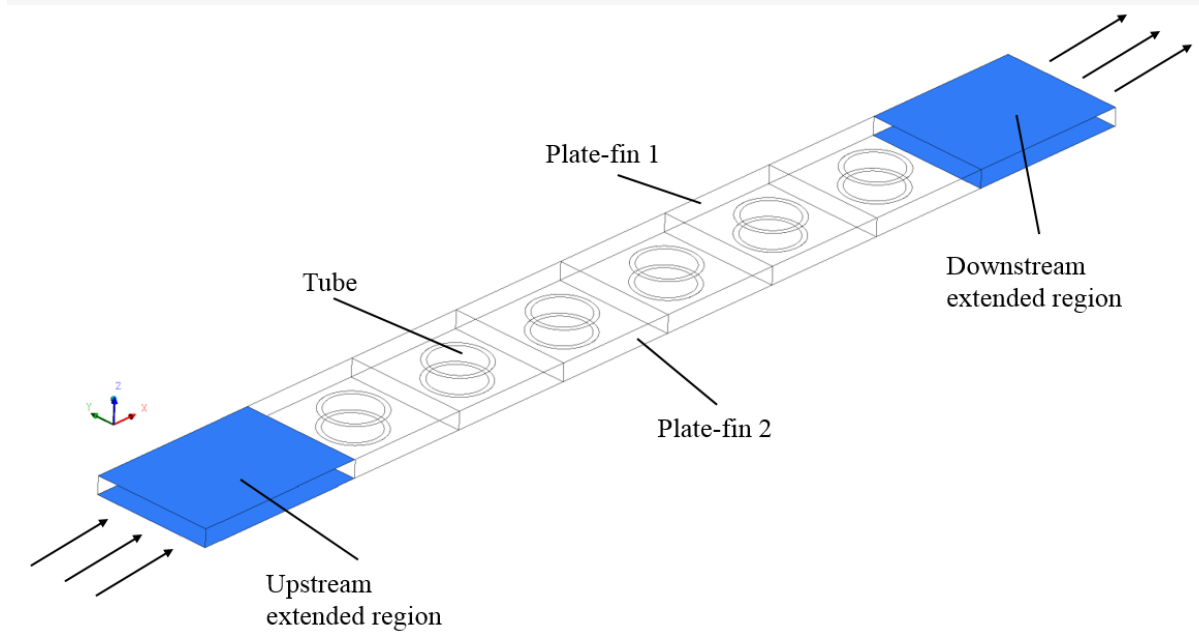

Fig. 1. Computational domain of plate fin and tube heat exchanger.

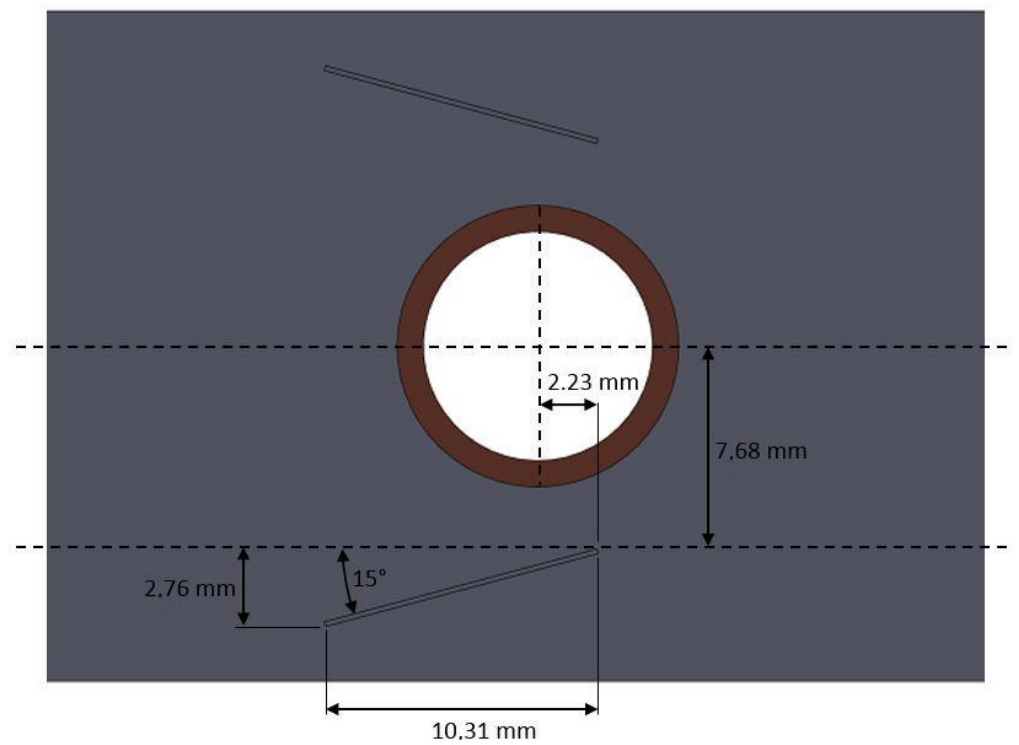

Fig. 2. Top view of the computational domain plate fin and tube heat exchanger with vortex generator.

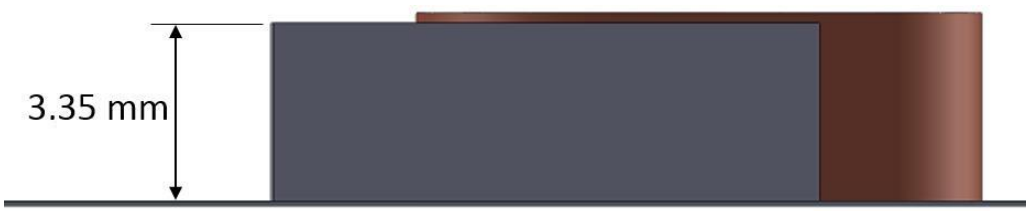


Fig. 3. Schematic of the computational domain plate fin and tube heat exchanger with rectangular winglet pairs (RWPs) of vortex generator.

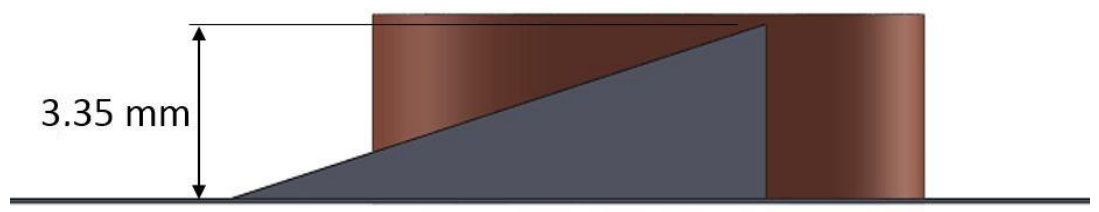

Fig. 4. Schematic of the computational domain plate fin and tube heat exchanger with delta winglet pairs (DWPs) of vortex generator.

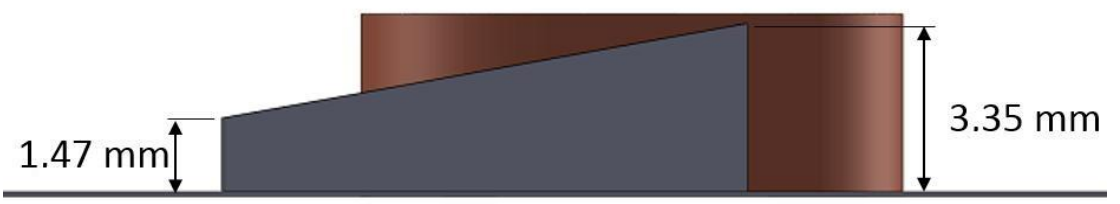

Fig. 5. Schematic of the computational domain plate fin and tube heat exchanger with trapezoid winglet pairs (TWPs) of vortex generator.

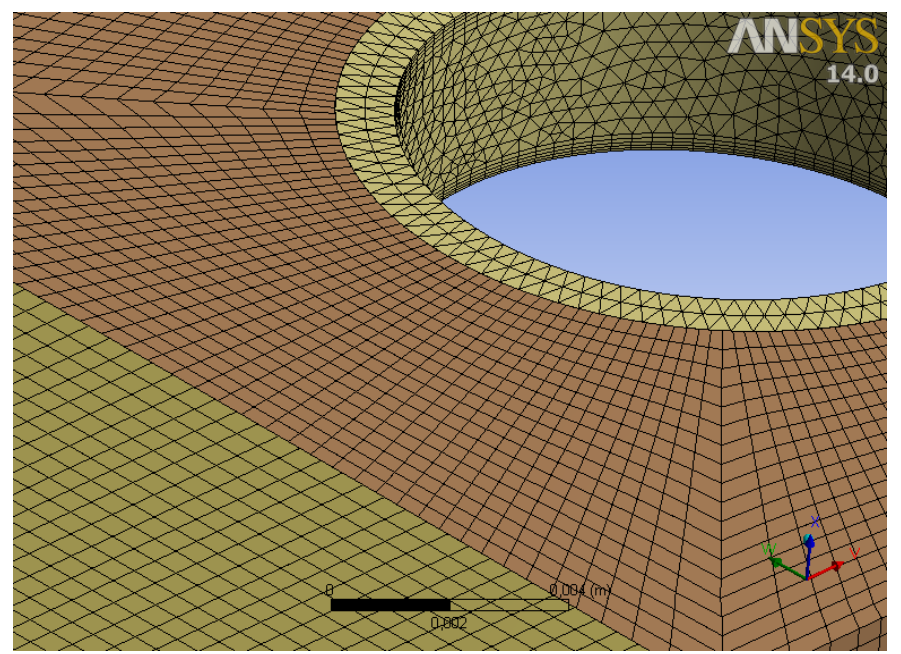

Fig. 6. Meshing of plate fin and tube heat exchanger.

Based on the governing equations of continuity, momentum and energy for three dimensional, constant material properties, laminar and steady forced convection flow can be expressed as follows:

Continuity equation : $\frac{\partial}{\partial x_{i}}\left(\rho u_{i}\right)=0$

Momentum equation : $\frac{\partial}{\partial x_{i}}\left(\rho u_{i} u_{k}\right)=\frac{\partial}{\partial x_{i}}\left(\mu \frac{\partial u_{k}}{\partial x_{i}}\right)-\frac{\partial p}{\partial x_{k}}$

Energy equation : $\frac{\partial}{\partial x_{i}}\left(\rho u_{i} T\right)=\frac{\partial}{\partial x_{i}}\left(\Gamma \frac{\partial T}{\partial x_{i}}\right)$ 
Where : $\Gamma=\frac{\lambda}{c_{p}}$

The computational domain consists of upstream extended region, fluid and tube region, and downstream extended region (see Figure 1). The boundary conditions for all surfaces were described as follows:

At the inlet boundary and upstream extended region:

$u=u_{\text {in }}=$ const $, \quad v=w=0, \quad T=T_{\text {in }}=$ const

At the upper and lower boundaries:

$\frac{\partial u}{\partial z}=\frac{\partial v}{\partial z}=0, \quad w=0, \quad \frac{\partial T}{\partial z}=0$

At the front and back boundaries:

$\frac{\partial u}{\partial y}=\frac{\partial v}{\partial y}=0, \quad v=0, \quad \frac{\partial T}{\partial y}=0$

For boundary conditions at the upper and lower boundaries and front and back boundaries are the same as at inlet boundary and upstream extended region.

At the outlet boundary:

$$
\frac{\partial u}{\partial x}=\frac{\partial v}{\partial x}=\frac{\partial w}{\partial x}=\frac{\partial T}{\partial x}=0
$$

At the fin and tube region for the upper and lower boundaries:

$u=v=w=0, \quad \frac{\partial \mathrm{T}}{\partial \mathrm{z}}=0$

At the fluid region in the front and back boundaries

$\left(\frac{\partial u}{\partial y}\right)=\left(\frac{\partial w}{\partial y}\right)=0, \quad v=0, \quad \frac{\partial T}{\partial y}=0$

At the fin surface region:

$u=v=w=0, \quad \frac{\partial \mathrm{T}}{\partial \mathrm{y}}=0$

At the tube region:

$u=v=w=0, \quad \mathrm{~T}=\mathrm{T}_{\mathrm{w}}=$ const

\section{Result and discussion}

Nusselt numbers are used to represent heat transfer performance. Figure 7 showed the Nusselt number increased with enhancement of Reynolds number [3-5]. The use of vortex generators can improve heat transfer performance. Vortex generators can provoke the formation of useful longitudinal vortices that increased flow mixing while reducing the 
wake size that impacted on increased heat transfer performance [6]. The use of RWPs generated the highest performance because it had the most extensive heat transfer surface while producing the most powerful longitudinal vortices compared to the use of DWPs and TWPs [7]. The more surface area in contact with the working fluid, so the higher heat transfer performance was obtained [2]. Figure 8 showed the increasing pressure drop in each case of simulation to enhance of Reynolds number. Increased heat transfer performance usually had an increased pressure drop effect [3]. Increased pressure drop occurred because the use of vortex generator can produce longitudinal vortices; thus, the working fluid moves longer in the heat exchanger than without the vortex generator.

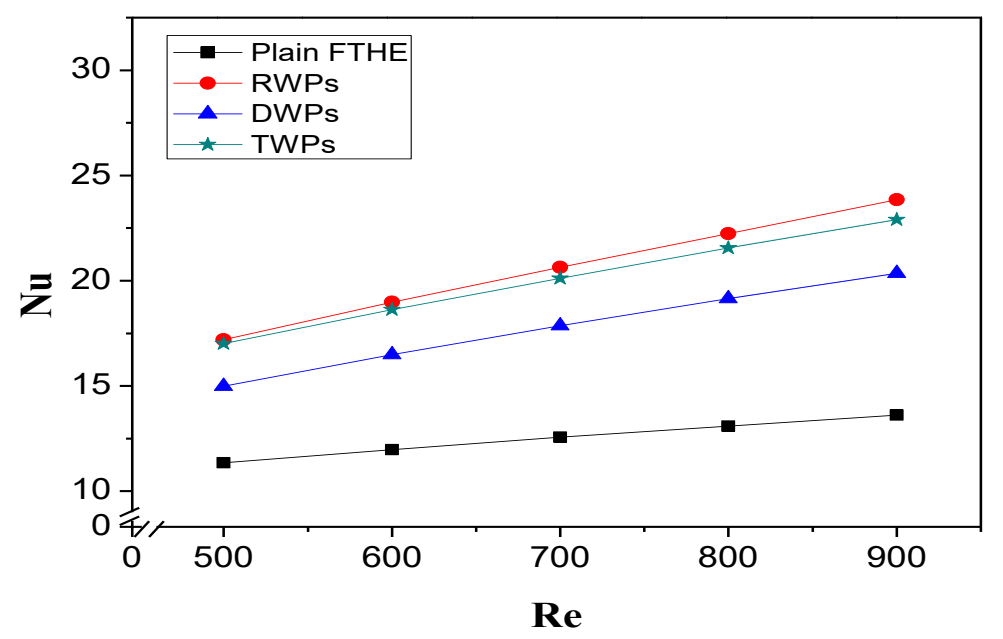

Fig. 7. Effect of vortex generator types on Nusselt numbers vs Reynolds numbers.

The use of vortex generators can decrease the magnitude of increased pressure drop in some specific cases [3]. It was due to the delay of separation of the flow around the tube by longitudinal vortices that can carry fluids with high momentum to the wake portion behind the tube [8]. The amount of pressure drop was influenced by the longitudinal vortices generated by the vortex generator. The larger the surface of the vortex generator conduced the greater of longitudinal vortices formed [7]. 


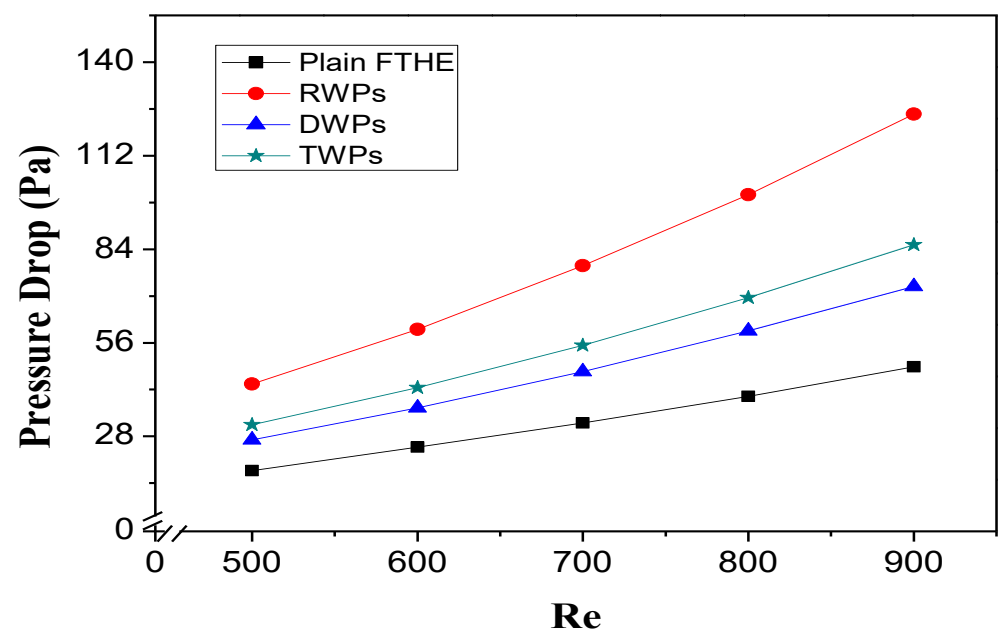

Fig. 8. Effect of vortex generator types on pressure drop vs Reynolds numbers.

In Figure 9 showed velocity contour on RWPs vortex generator. Compared with another velocity contour, using RWPs had highest of stream velocity in wake region around. The highest of stream velocity indicated the formation of longitudinal vortices that the most powerful when compared with other variations of vortex generators. The use of RWPs vortex generator resulted the highest of heat transfer performance compared to other variations of vortex generator. The use of DWPs vortex generators can increase fluid flow mixing with relatively low flow resistance; thus, the fluid flow mixing in the wake region and downstream of the vortex generator can improve the performance of heat transfer [9].

The use of TWPs vortex generator provided more mixed working fluid in the downstream area of each vortex generator while increasing the fluid flow rate in the area around the wake region. Increased velocity was occurred due to the formation of longitudinal vortices were strong. Strong longitudinal vortices can improve heat transfer performance [3]. When compared to other variations of the vortex generator, the use of TWPs vortex generator generated more smooth distribution of flows than RWPs and CWPs vortex generators while producing longitudinal vortices that were stronger than the use of DWPs vortex generators.

The difference in the geometry of the vortex generator produced different of temperature distribution of working fluid. The temperature contour of Figure 10 showed the use of vortex generator RWPs can increase the temperature distribution in the wake region. In addition, the use of RWPs vortex generator had the characteristic to change the working fluid temperature drastically when the working fluid passed through the vortex generator. The temperature change was indicated by the temperature difference at the front and back of the first to fourth tube. With the temperature distribution characteristics obtained from the use of the vortex generator RWPs, the working fluid can have a temperature almost equal to the FTHE temperature as the working fluid passed through the fifth tube and had the same temperature as FTHE as it flowed in the upstream portion of the sixth tube. Decrease in working fluid temperature occurred due to the strongest longitudinal vortices produced by RWPs vortex generator [3]. 


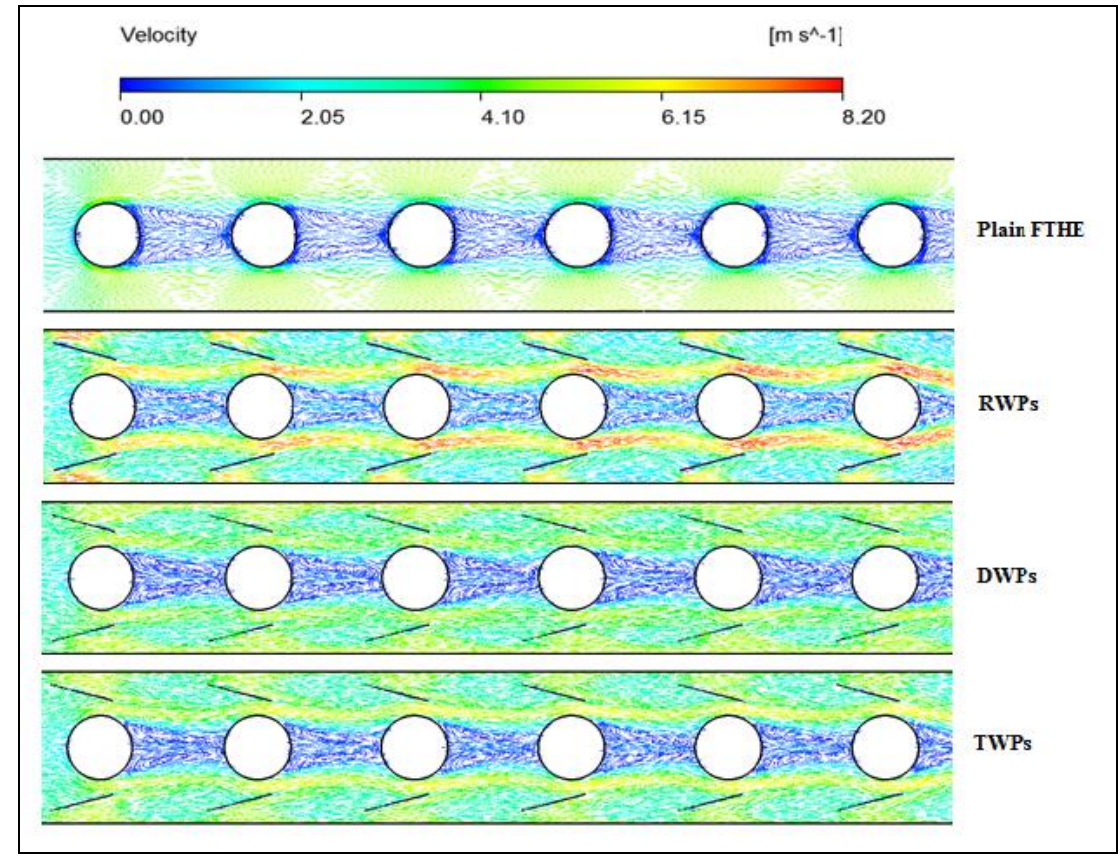

Fig. 9. Contour of velocity for vortex generator types at the highest Reynolds numbers.

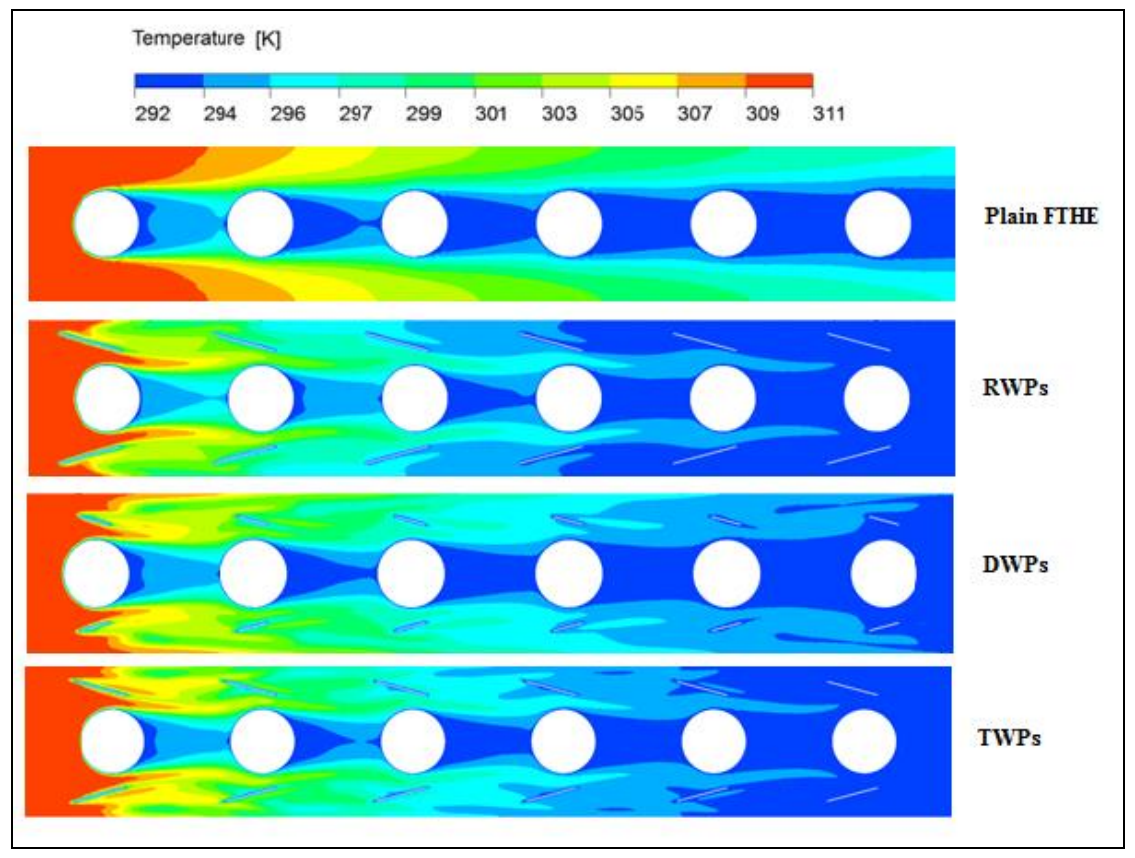

Fig. 10. Contour of temperature for vortex generator types at the highest Reynolds numbers.

The use of DWPs vortex generator resulted weak longitudinal vortices. It provided temperature change of the working fluid up to the sixth tube. Although temperature change occurred slowly, the working fluid flow may leave the FTHE at a temperature equal to the FTHE temperature [10]. The use of TWPs vortex generator produced a higher temperature 
gradient compared to the use of DWPs vortex generator but lower when compared to the use of RWPs vortex generator. Compared with the use of DWPs vortex generator, the use of TWPs vortex generator can produce a more even distribution of temperature and can make the working fluid had the same temperature as the FTHE temperature when the working fluid passed through the sixth tube.

\section{Conclusion}

In this study, a three-dimensional numerical simulation was performed to examine the effect of vortex generators between rectangular winglet, delta winglet, and trapezoidal winglet vortex generators in plate fin and tube heat exchanger. The main conclusion based on the result of Nusselt number and pressure drop were summarized as follow:

i. The use of vortex generators can improve heat transfer performance. Vortex generators can provoke the formation of useful longitudinal vortices that increased flow mixing while reducing the wake size that impacted on increased heat transfer performance. The use of RWPs generated the highest performance because it had the most extensive heat transfer surface while producing the most powerful longitudinal vortices compared to the use of DWPs and TWPs.

ii. Increased pressure drop occurred because the use of vortex generator can produce longitudinal vortices; thus, the working fluid moves longer in the heat exchanger than without the vortex generator. The amount of pressure drop was influenced by the longitudinal vortices generated by the vortex generator.

\section{References}

1. M.K. Akliabadi, S. Zangouei, F. Hormozi, Int. J. Therm. Sci., 88:180-192(2015). https://www.sciencedirect.com/science/article/pii/S1290072914002853

2. S.R. Hiravennavar, E.G. Tulapurkara, G. Biswas, Int. J. Heat Fluid Flow, 28,2:299-305(2007).

https://www.sciencedirect.com/science/article/pii/S0017931003000474?via\%3Dihub

3. Y.L. He, P. Chu, W.Q. Tao, Y.W. Zhang, T. Xie, Appl. Therm. Eng., 61,2:770-783(2013). https://www.sciencedirect.com/science/article/pii/S1359431112001433

4. C. Min, C. Qi, X. Kong, J. Dong, Int. J. Heat Mass Transfer, 53:3023-3029(2010). https://www.sciencedirect.com/science/article/pii/S0017931010001675

5. B. Lotfi, M. Zeng, B. Sundén, Q. Wang, Int. J. Energy, 73:233-257(2014). https://www.sciencedirect.com/science/article/abs/pii/S0360544214007142

6. Y.L. He, Y. Zhang, Adv. Heat Transfer, 44:119-185(2012) https://www.tib.eu/en/search/id/tema\%3ATEMA20130100820/Advances-andoutlooks-of-heat-transfer-enhancement/

7. G. Zhou, Q. Ye, Appl. Therm. Eng, 37:241-248(2012). https://www.researchgate.net/publication/257526021 Experimental investigations of thermal and flow characteristics of curved trapezoidal winglet type vortex genera tors

8. G. Zhou, Z. Feng, Int. J. Therm. Sci, 78:26-35(2014). https://www.researchgate.net/publication/259521213 Experimental_investigations_of heat transfer_enhancement by plane and curved_winglet type_vortex_generators_w ith_punched_holes 
9. L. Tian, Y. He, Y. Tao, W. Tao, Int. J. Therm. Sci, 48,9:1765-1776(2009). https://www.sciencedirect.com/science/article/pii/S1290072909000234

10. M.J. Li, W.J. Zhou, J.F. Zhang, J.F. Fan, Y.L. He, W.Q. Tao, Int. J. Heat Mass Transfer, 70:734-744(2014).

https://www.researchgate.net/publication/273621866 Heat transfer and pressure perf ormance_of_a_plain_fin_with_radiantly_arranged_winglets_around_each_tube_in_fin -and-tube heat transfer surface 